\title{
Caracterização e contextualização histórica: moradores em situação de rua, o fenômeno da vulnerabilidade
}

\author{
Historical characterization and context: Homeless people, the phenomenon of \\ vulnerability.
}

\author{
Eliane Terezinha Giacomelli ${ }^{1 *}$, Tania Maria Rechia Schroeder ${ }^{1}$
}

\begin{abstract}
RESUMO
A utilização da rua como espaço de moradia e permanecia é uma realidade cada vez mais observável e tampouco um fenômeno só brasileiro. Viver em um cenário de extrema vulnerabilidade e risco e degradante, porém, cada vez mais real para inúmeras pessoas ao redor do mundo, ocasionadas por diversas causas. Assim, destaca-se como objetivo central desse estudo a contextualização histórica e a caracterização dos moradores em situação de rua. Trata-se de um estudo qualitativo, de caráter exploratório descritivo, construída a partir da revisão bibliográfica. Os estudos analisados demostram que, mesmo diante das especificidades e a complexidade que envolve o morador de rua, os mesmos continuam ocupando espaços e as políticas produzindo assujeitamento. Sob um fenômeno estigmatizante, as ações continuam assistencialistas, autoritárias e sob uma perspectiva de higienização. A partir dos resultados encontrados considera-se a necessidade de uma política intersetorial que abarque ações junto aos equipamentos e serviços em rede intensificada no que tange a prevenção da exclusão e a promoção dos resultados mais eficazes aos que vivem à margem das políticas de acesso e cuidado.
\end{abstract}

Palavras-chave: Caracterização Histórica; Exclusão Social; Morador em Situação de Rua; Políticas públicas; Vulnerabilidade.

\begin{abstract}
The use of the street as a space for housing and permanence is an increasingly observable reality and not just a Brazilian phenomenon. Living in a scenario of extreme vulnerability and risk is degrading, however, increasingly real for people around the world, entailed by many causes. Therefore, the main objective of this study is the historical contextualization and characterization of homeless people. This work is a qualitative study, with an exploratory descriptive character, built from the bibliographical review. The analyzed studies demonstrate that, despite the specificities and complexity that involve the homeless, they continue to occupy spaces and the policies continue producing subjection. Under a stigmatizing phenomenon, the actions remains assistentialist, authoritarian and from a higyenation perspective. Based on the results found, there must be an intersectoral policy that encompasses actions with equipment and services in an intensified network regarding the prevention of exclusion and the promotion of more effective results for those who live outside the policies of access and care.
\end{abstract}

Keywords: Historical characterization. Social exclusion. Homeless resident. Public policies. Vulnerability.

\footnotetext{
${ }^{1}$ Universidade do Oeste do Paraná - UNIOESTE.* E-mail: elianetg@ hotmail.com
} 


\section{INTRODUÇÃO}

A população em situação de rua vive o cotidiano marcado pela escassez e exclusão social. Marcam e demarcam espaços, garantindo sua permanência, sobretudo para assegurar sua alimentação, higiene e sustento. Têm em comum, características como o uso de drogas, comorbidades psiquiátricas, vínculos familiares interrompidos, fatores que contribuem para o processo de vulnerabilidade (BRASIL, 2008).

A utilização da rua como espaço de moradia e permanência é uma realidade cada vez mais observável. Por não possuírem moradia regular, utilizam locais públicos, áreas degradadas e desabitadas, como espaços habitacionais de forma permanente ou temporária. O cenário da Rua constitui parte de uma complexa e paradoxal rede social e de sociabilidades desenvolvidas nesses espaços que, na maioria das vezes, são hostis, insalubres, perigosos e violentos (BRASIL, 2008; BRASIL, 2011).

É possível identificar nos documentos oficiais brasileiros, um conjunto de significados que contemplam um grupo bastante heterogêneo, constituídos por várias representações e estereótipos sociais, tais como: vagabundos, mendigos, desocupados, drogados, meliantes, violentos, ladrões, andarilhos, trecheiros, pardais, dentre outros sujeitos que fazem da rua seu principal espaço de convivência (BRASIL, 2008).

Tal população vive num cenário complexo e de extrema vulnerabilidade e risco. Nesse sentido, faz-se necessário compreender o contexto vivido, valores, crenças, sentidos e percepções, para então planejar e promover ações que visem à redução de vulnerabilidades e de riscos à saúde, e posteriori, fomentar discussões junto aos serviços de referência e articular intervenções integradas com a rede de serviço diante da necessidade dessa população.

\section{METODOLOGIA}

O presente estudo se enquadra no método qualitativo, de caráter exploratório descritivo, constituída a partir da revisão bibliográfica. Destaca-se que os dados apresentados no presente artigo, fazem parte de um dos capítulos teóricos da dissertação de mestrado de um dos autores, intitulada: Moradores em situação de rua: uma etnografia urbana da cidade de Cascavel/Pr, submetido ao Comitê de Ética em Pesquisa da Universidade Estadual do Oeste do Paraná (UNIOESTE) e aprovado com o CAAE $\mathrm{n}^{\circ}$ 34699320.7.0000.0107 e conforme Parecer $n^{\circ}$ 4.184.449. 
Como objetivo central deste estudo, apresenta-se a contextualização histórica e a caracterização dos moradores em situação de rua. Para compreender o fenômeno estudado foi desenvolvida uma revisão de literatura que objetivou identificar artigos científicos sistematizando os estudos de referências e as reflexões sobre o tema proposto.

Para as buscas, foram utilizadas as seguintes palavras-chave: "moradores de rua"; "moradores em situação de rua"; "vulnerabilidade social"; e "uso de drogas". Durante o refinamento das buscas, identificou-se que os descritores "Morador de rua" e "Morador em situação de rua", por vezes, aparecem em maior ou menor quantidade de trabalhos disponibilizados nas plataformas e, por isso, utilizou-se as duas terminologias ao longo do texto.

Excluíram-se os estudos que não versavam acerca da temática em discussão. Foram considerados, para esta revisão, estudos publicados e indexados na plataforma Scientific Electronic Library Online (SCIELO), a qual foi escolhida por ser uma das bases mais difundidas no ambiente acadêmico, o banco teses e dissertações da Coordenação de Aperfeiçoamento de Pessoal de Nível Superior (CAPES) e o Google Acadêmico. Como critério de seleção das obras utilizadas foi considerado apenas os estudos publicados em periódicos qualis A.

\section{CONTEXTUALIZAÇÃO HISTÓRICA DO MORADOR EM SITUAÇÃO DE RUA}

Em países europeus, observam-se um aumento significativo de "sem-teto". Entre os países com o maior aumento de habitantes sem abrigo, segundo FENTASA (2018), estão a Inglaterra (169\% entre 2010 e 2016), a Irlanda (145\% entre 2014 e 2017) e a Bélgica (96\% entre 2008 e 2016). Os países que sofreram os aumentos mais extremos nos custos de habitação são: Bulgária, Inglaterra, Portugal, República Tcheca e Polônia. Em toda a Europa, os "sem-teto" vivem cerca de 30 anos menos do que o resto da população. Em média, eles moram nas ruas por 10,3 anos. A Federação Europeia das Associações Nacionais (FENTASA), que trabalha com os "sem-teto", confirmou a tendência crescente com um estudo recente que aponta uma piora da crise social e um crescimento cada vez maior da desigualdade entre ricos e pobres (FENTASA, 2018).

Estudo apontado por Borysow, Conill e Furtado (2017) assinalam que são milhares os números de pessoas em situação de rua no Brasil, Portugal e Estados Unidos. Foram identificadas fragilidades e a falta de adesão nos atendimentos devido ao preconceito e estigmatização por parte dos que os atendem. 
No Brasil, de acordo com índices apontados pelo Ministério do Desenvolvimento Social e Combate à Fome, cada vez mais homens, mulheres e crianças utilizam as ruas como moradia.

O primeiro Censo Pop Rua e pesquisa ocorreu entre agosto de 2007 a março de 2008 em 23 capitais e 48 municípios com mais de 300 mil habitantes. Essa pesquisa identificou 31.922 pessoas adultas (acima de 18 anos) em situação de rua (BRASIL, 2008).

Segundo o Instituto Brasileiro de Geografia e Estatística (IBGE, 2018), a população de rua deve ficar fora do Censo 2020. O assunto está em pauta de discussão, mas sem data prevista para sua realização. Nas pesquisas feitas pelo IBGE, somente são consideradas como dados de pesquisa os domicílios permanentes. Segundo eles, identificar essa população - morador em situação de rua, requer uma grande mobilização, principalmente em um país como o Brasil (MELITO, 2018).

Conforme Natalino (2016), não se tem dados oficiais atualizados sobre essa população no Brasil. "O Brasil não conta com dados oficiais sobre a população em situação de rua. Esta ausência prejudica a implementação de políticas públicas voltadas para este contingente e reproduz a invisibilidade social da população de rua no âmbito das políticas sociais" (IPEA, 2016, p. 7).

Constata-se um aumento significativo de moradores de rua, identificados pelo Censo de 2020 do Instituto de Pesquisa Econômica Aplicada (IPEA). O fato de o Brasil permanecer sem uma contagem oficial é atribuído às dificuldades relacionadas, sobretudo, à sua extensão territorial e sua diversidade cultural (NATALINO, 2020). Em razão disso, a população de rua fica sujeita às consequências da invisibilidade social, ficando a margem do cuidado em saúde por conta da falta de políticas públicas que contemplem integralmente essa população. A partir desse fator preponderante:

Dado o contexto da pandemia a necessidade de ofertar a esses espaços públicos de acolhimento adequado as normas sanitárias de distanciamento social - o que implica, por exemplo, reduzir o número de leitos nos abrigos existentes, tornar-se imperativo contornar tal dificuldade (NATALINO, 2020, p. 7).

Mesmo diante de tais dificuldades, Natalino reforça:

[...] embora as dificuldades sejam incontáveis, no momento a melhor forma de estimar essa população e sua evolução ao longo dos anos é 
por meio da compilação, análise e modelagem estatística de dados oficiais coletados pelos mais de 5.500 municípios da federação. [...] incorpora-se a dinâmica temporal na nova estimativa, o que permitirá a atualização periódica dos dados a partir de agora (NATALINO, 2020, p. 7).

Importante salientar o quanto é difícil captar dados em populações sem moradias convencionais e, desta forma, evidencia-se o esforço em dar visibilidade a eles, por meio do cadastro único que demonstra maior confiabilidade dos dados existentes (NATALINO, 2020, p.7).

Para Natalino (2020), o aumento significativo da população em situação de rua, fenômeno, esse, vinculado à crise econômica e ao desemprego, se agravou ainda mais neste cenário pandêmico de enfrentamento à COVID-19. Assim, esta nova realidade deverá ser monitorada, pois os dados estatísticos de março de 2020 contabilizaram 221.869 mil pessoas em situação de rua no Brasil.

Nesse sentido, a formatação e qualidade dos dados atualizados permitirão realizar essa estimativa sempre que necessário, possibilitando analisar as demandas, em especial neste cenário pandêmico de enfrentamento à Covid-19 (NATALINO, 2020, p.20).

A falta de uma contagem oficial revela a fragilidade em relação à promoção de ações de reconhecimento dessa população, bem como a falta de implantação e/ou implementação de políticas que atendam essas necessidades. A escassez de dados traz, como consequência, a persistência da invisibilidade social dessa população.

\section{CARACTERIZAÇÃO DO MORADOR EM SITUAÇÃO DE RUA}

Para Frangella (2004) e Feltes (2017), o suposto e provável surgimento do reconhecimento da população de rua aparecem na história acompanhada ao desenvolvimento urbano - surgimento dos grandes centros, à migração de camponeses e desemprego, assim como catástrofes naturais e, com isso, as migrações de estrangeiros vivenciados na contemporaneidade. O hábito de caminhar para algum lugar é um movimento e possibilidade de cidadania, que nos liga à liberdade, observado desde a antiguidade (ECKERT e ROCHA, 2020).

Segundo Magni (1997):

A ideia vigente de que a população que vive na rua é migrante, oriunda da zona rural ou de cidades do interior, buscando adaptar-se ao meio urbano, não é de todo desprovida de razão. No entanto limita-se o assunto à temática do êxodo e ainda oculta uma questão mais 
importante: embora haja algumas exceções, o sujeito que passa a viver na rua tem que se deslocar constantemente por pressão ou por conveniência, de modo a se adaptar as condições sócio ecológicos do meio urbano (MAGNI, 1997, p. 35).

Magni (1997) reforça que essas situações os distanciam do mercado de trabalho e dos vínculos das relações familiares. Portanto, tem como possibilidade a ocupação de espaços sub habitacionais. Tais deslocamentos são comuns e similares aos movimentos migratórios, permanecendo provisoriamente por diversos territórios ao longo da história da humanidade.

O constante recomeço em que quase nada é estável ou permanentemente, a fragilidade de seus vínculos com o trabalho, a família, a moradia, revelam uma vida marcada pela fragmentação (MAGNI, 1997, p. 35).

Essa forma de habitarem ou se movimentarem nos inclina a olhá-los na experiência cotidiana permanente de vulnerabilidade social, emocional e física. Assim, o termo "vulnerabilidade" expressa uma multiplicidade de possibilidades multifatoriais, de cunho individual, relacionados ao processo histórico e à própria história de vida, assim como a pobreza traz à luz as desigualdades sociais (BORYSOW; CONILL; FURTADO, 2017; SANCHEZ e BERTOLOZZI, 2007). A utilização do termo ou mudança de "risco" para "vulnerabilidade" pressupõe a compreensão e visão do homem e de sociedade.

Para Mendes, Ronzani e Paiva (2019):

[...] no que tange a população em situação de rua, os processos de marginalização são mais complexos do que a ausência de lar, e dizem respeito a trajetórias marcadas por opressões e que resultam em quadros de vulnerabilidade. Não é possível, dessa forma, afirmar que, mesmo em não situação de rua, não havia vulnerabilidades outras, como a afetiva, a étnico racial, de gênero, de violências e de discriminação. Todas elas resultam em uma sociabilidade que oprime e se referem à gestão da pobreza na sociedade brasileira (MENDES; RONZANI; PAIVA, 2019, p. 10).

Essa população estabelece, com a rua, o seu espaço de convivência e, nela, as suas relações privadas, o que a caracteriza como população em situação de rua (BRASIL, 2008). Segundo Magni (1995), esse termo é utilizado na França como "pessoas semdomicilio" (PSD) ou "sem domicilio fixo" (SDF) que, segundo a autora, é ausência de um lar ou residência. 
Assim, os espaços públicos são utilizados como extensão ou modelos das casas convencionais, passam a ter finalidades domésticas, em que realizam atividades naturais como dormir, cozinhar, excretar e higienizar-se. Comumente se apresentam com vestes sujas, rasgadas, malcheirosos e calçados surrados, demonstrando, assim, a conjuntura da vulnerabilidade pela sua condição, expondo suas singularidades nos pertences que carregam. Estão expostos à fragilidade de seu estado físico, mental e social (BRASIL, 2011). Essa sujeira é, também, segundo Frangella (2004):

Fruto do suor de restos de comida que grudam em seu corpo e cabelo, do uso do crack. É fruto do descuido que vem da rapidez que circulam de um lugar ao outro. [...] Vem da exposição ao sol, ao frio, ao vento, à chuva, à poluição e ao asfalto que tudo arranha. Vem por fim da adesão completa a movimentação e dinâmica das ruas (FRANGELLA, 2004, p. 244).

Ainda nesse sentido Rui (2012) destaca que a sujeira,

[...] vem ainda, do contato rotineiro com o lixo urbano, da proximidade corporal com os cachorros e gatos da rua, com os ratos que invadem suas habitações provisórias. Vem da conjugação entre o local de excreção e o de alimentação, e, ainda dormem direto no chão ou sob papelões encontrados na rua, enrolados ou não em cobertores (RUI, 2012, p. 284).

Rui (2012), afirma que quanto maior o tempo na rua, maior é a espessura da sujeira neste processo, o autor afirma que “[...] os pés vão se tornando ásperos e empoeirados, as unhas ficam pretas, grossas e grandes, os cabelos rançosos, a pele se torna encardida.” (p. 38-45). Ainda para o autor "[...] quem vivencia no corpo esse processo fica alheio a ele." (p. 38-45).

Campos (2018) conclui, em seus estudos, que viver nas ruas produz identificação, relações e convivência. Os moradores de rua vivenciam relações de intolerância, indiferença, abandono, preconceito relacionado à falta de higiene pessoal, ao uso de drogas e associação à criminalidade, colocando-os ainda mais à margem da sociedade. Todo o episódio traumático instiga para a mudança, a errância, seja para encontrar novos caminhos, seja para conquistar, buscar novas experiências ou fuga da rotina. Marx (18181883) argumentara que:

[...] que ao lado dos devassos arruinados, dos meios de existência duvidosos de aventureiros, de escórias corrompidas da burguesia, encontramos aí vagabundos (...), gatunos, charlatães (...), gigolôs, gerentes de casas de prostituição, carregadores, escrivinhadores, tocadores de órgão, vendedores de quinquilharias, funileiros, mendigos, 
em resumo, toda essa massa confusa, decomposta, flutuante que os franceses chamam la boème (MARX, apud MAFFESOLI, 2001, p. 61).

Nessa linha de raciocínio os autores Matiello e Ramos (2018) e Moura, Ferreira e Ximenes (2016a), afirmam que os estigmas impedem a possibilidade de chegarmos à subjetividade dos moradores de rua, destituindo sua singularidade. Para Goffman (1993), o corpo pode carregar em si uma marca de estigma, recurso utilizado pelos gregos, tais povos evidenciavam sinais corporais que representassem alguma coisa de extraordinário ou de ruim, um status moral de quem os representava. Assim,

[..] os sinais eram feitos com cortes ou fogo no corpo e avisavam que o portador era um escravo, um criminoso ou traidor uma pessoa marcada, ritualmente poluída, que devia ser evitada; especialmente em lugares públicos. Mais tarde, na Era Cristã, dois níveis de metáfora foram acrescentados ao termo: o primeiro deles referia-se a sinais corporais de graças divina que tomavam a forma de flores em erupção sobre a pele; o segundo, uma alusão médica a essa alusão religiosa, referia-se a sinais corporais de distúrbio físico. Atualmente, o termo é amplamente usado de maneira um tanto semelhante ao sentido literal original, porém é mais aplicado à própria desgraça do que à sua evidência corporal (GOFFMAN, 1993, p.05).

Considerando os estigmas, esses, podem produzir nos sujeitos, perdas e sofrimento psicológico e, segundo Alcantara, Abreu e Farias (2015); Moura, Ferreira e Ximenes (2016b), o não reconhecimento de sua identidade, portanto de sua condição de cidadão, pode conduzir, ainda mais, a comportamentos autodestrutivos, como o uso abusivo de drogas,

[...] outras questões como estereotipias, preconceitos e estigmas da sociedade e dos agentes do Estado que rotulam essa população como marginais, doentes, drogados, loucos, sujos, mendigos e delinquentes também são aspectos agravantes que restringem de forma drástica as possibilidades de reintegração à sociedade (MATIELLO e RAMOS, 2018, p.68-69).

Montiel et. al. (2015), compararam a prevalência de tendências de personalidades patológicas entre moradores de rua com outros grupos. A pesquisa foi planejada tendo em vista a carência de estudos no Brasil que tratassem dos transtornos de personalidade em moradores de rua. Os resultados evidenciaram maior atenção para a saúde mental e a moradia, demonstrando a necessidade e o reordenamento para as políticas públicas para essa população. O autor propõe que esse assunto deve ser tratado também no âmbito da saúde, pois outros países, como Estados Unidos e Reino Unido, 
[...] chamam a atenção para que o cuidado com a saúde mental do morador de rua seja primário ao cuidado deste problema social e tem um papel importante na quebra da manutenção deste. [...] indivíduos acometidos de transtorno antissocial apresentam comportamentos e atos delinquentes, que constituem detenção (MONTIEL, et al., 2015, p.497).

Segundo Aldridge et. al. (2018a), a saúde inclusiva deve ser pauta de discussão, com o objetivo de corrigir as desigualdades sociais e de saúde entre as populações mais vulneráveis e excluídas. Essas, por sua vez, apresentam diversos fatores de risco e aumento significativo de percentuais de morbidade e mortalidade. Nesse estudo, os autores identificam diversas possibilidades de intervenções para melhorar a saúde física e mental e uso de substâncias. No entanto, observam-se poucas intervenções estruturais tais como a moradia, o emprego e o apoio legal, os quais poderiam prevenir tanto a exclusão como promover a recuperação.

Os autores Fitzpatrick, Bramley e Johnsen (2013) identificam cinco fatores dentro da população "sem-teto" e relacionados à sua complexidade vivencial. São elas: falta de moradia, uso de substâncias, cuidados institucionais, atividades de cultura de rua e eventos adversos da vida. Os autores relacionam esses fatores aos traumas da infância, ao uso de entorpecentes e problemas de saúde mental.

Aldridge et. al. (2018b), em seus estudos sobre mortalidade e morbidade, identificaram que as taxas de mortalidade aumentaram significativamente nas doenças, como: envenenamento, hepatite $\mathrm{B}$, tuberculose, saúde mental, doenças cardíacas, respiratórias e outras causas extremas.

Tais estudos demonstram que, mesmo diante das especificidades e a complexidade que envolve o morador de rua, os mesmos continuam ocupando espaços e as políticas produzindo assujeitamento. Sob um fenômeno estigmatizante, as ações continuam assistencialistas, autoritárias e sob uma perspectiva de higienização.

Silva (2006) pontua que, este fenômeno esta associado à estrutura capitalista e a uma multiplicidade de fatores contemporâneo, e de uma sociedade preconceituosa. Este possui características vinculadas aos espaços em que os mesmos se encontram. Reforça ainda, que este fenômeno é por si naturalizado e carente de informações e dados, consequentemente sem politicas efetivas ao seu enfretamento (SILVA, 2006, p.95).

\section{CONSIDERAÇÕES FINAIS}


Considerando o tema destaca-se a relevância cientifica e social dos estudos produzidos, a importância de tais estudos na qualificação dos profissionais atuantes com pessoas em situação de rua, bem como nas maneiras como se dão e se constroem as relações entre a população em situação de rua e a cidade, com o território em que vivem.

Tais estudos demostram que, mesmo diante das especificidades e a complexidade que envolve o morador de rua, os mesmos continuam ocupando espaços e as políticas produzindo assujeitamento. Sob um fenômeno estigmatizante, as ações continuam assistencialistas, autoritárias e sob uma perspectiva de higienização.

A relação que se produz ao viver nas ruas se dá por uma essência normativa e padronizada que parte de um modelo excludente, identitário e previsível por si só. Um estereótipo enunciado estigmatizante associado ao uso de drogas, às comorbidades psiquiátricas, ao crime e à violência.

Diante da desigualdade e da complexidade identificada nesta população, constatase a necessidade de uma política intersetorial que abarque ações junto aos equipamentos e serviços em rede intensificada no que tange a prevenção da exclusão e a promoção dos resultados mais eficazes aos que vivem à margem das políticas de acesso e cuidado.

\section{REFERÊNCIAS}

ADORNO, R. C. F. et al. Etnografia da cracolândia: notas sobre uma pesquisa em território urbano. Saúde \& Transformação Social, Florianópolis, v. 4, n. 2, p. 04-13, 2013. Disponível em:

http://incubadora.periodicos.ufsc.br/index.php/saudeetransformacao/article/view/2246/2 646. Acesso em: 29 ago. 2020.

ALCANTARA, S. C., ABREU, D. P., FARIAS, A. A. Pessoas em situação de rua: Das trajetórias de exclusão social aos processos emancipatórios de formação de consciência, identidade e sentimento de pertença. Revista Colombiana de Psicología, Bogotá, v. $1, n$. 24, p. 129-143, 2015. Disponível em: https://doi.org/10.15446/rcp.v24n1.40659. Acesso em: 13 set. 2020 .

ALDRIDGE, R. W. et al. O que funciona na saúde da inclusão: visão geral de intervenções eficazes para populações marginalizadas e excluídas. The Lancet, v. 391, ed. 10117, p. 266-280, 2018a. Disponível em:

https://www.sciencedirect.com/science/article/pii/S014067361731869X. Acesso em: 13 set. 2020.

ALDRIDGE, R. W. et al. Morbidity and mortality in homeless individuals, prisoners, sex workers, and individuals with substance use disorders in high-income countries: a systematic review and meta-analysis. The Lancet, v. 391, n. 10117, p. 241-250, 2018 b. 
Disponível em: https://www.sciencedirect.com/science/article/pii/S014067361731869X. Acesso em: 13 de set. 2020.

BORYSOW, I. C.; CONILL, E. M.; FURTADO, J. P. Atenção à saúde de pessoas em situação de rua: estudo comparado de unidades móveis em Portugal, Estados Unidos e Brasil. Ciência Saúde Coletiva, Rio de Janeiro, v. 22, n. 3, p. 879-890.

2017. Disponível em: http://www.scielo.br/scielo.php?script=sci_arttext\&pid=S141381232017002300879\&lng=pt\&nrm=iso. Acesso em: 16 ago. 2020.

BRASIL. Decreto $\mathbf{n}^{\mathbf{0}}$ 7.637, de 08 de dezembro de 2011. Altera o Decreto $\mathrm{n}^{\mathbf{0}} 7.179$, de 20 de maio de 2010, que institui o Plano Integrado de Enfrentamento ao Crack e outras Drogas. Brasília, 2011a. Disponível em:

http://www.planalto.gov.br/ccivil_03/_Ato2011-2014/2011/Decreto/D7637.htm. Acesso em: 13 set. 2020.

BRASIL. Ministério da Saúde. Política Nacional para Inclusão Social da População em Situação de Rua. Brasília, 2008. Disponível em:

http://www.mpsp.mp.br/portal/page/portal/cao_civel/acoes_afirmativas/inclusaooutros/a a_diversos/Pol.Nacional-Morad.Rua.pdf. Acesso em: 13 de set. 2020.

CAMPOS, A. População de rua: um olhar da educação interprofissional para o não visível. Saúde e Sociedade, v. 27, p. 997-1003, 2018. Disponível em:

https://www.scielo.br/scielo.php?script=sci_abstract\&pid=S0104$12902018000400997 \& \operatorname{lng}=$ pt\&nrm=iso. Acesso em: 13 set. 2020.

ECKERT, C.; ROCHA, A. L. C. A arte de narrar as (nas) cidades: etnografia de (na) rua, alteridades em deslocamento. Hawò, v. 1, p. 1-52, 2020. Disponível em:

https://www.revistas.ufg.br/hawo/article/view/63521. Acesso em: 10 set. 2020.

FELTES, D. L. Zé Correto e a construção dos modos de existência do sujeito em situação de rua. 2017. 126 f. Dissertação (Mestrado em Ciências Socais) - Programa de Pós Graduação em Ciências Socias, Universidade Estadual do Oeste do Paraná, Toledo, 2017. Disponível em: http://tede.unioeste.br/handle/tede/3272. Acesso em: 08 set. 2020 .

FIORI. M. Uso de drogas: substâncias, sujeitos e eventos. 2013. 210 f. Tese (Doutorado em Ciências Sociais) - Instituto de Filosofia e Ciências Humanas, Unicamp, Campinas, 2013. Disponível em:

http://repositorio.unicamp.br/jspui/bitstream/REPOSIP/281261/1/Fiore_Mauricio_D.pdf . Acesso em: 10 ago. 2020.

FITZPATRICK, S.; BRAMLEY, G.; JOHNSEN, S. Caminhos para os sem-teto de exclusão múltipla em sete cidades do Reino Unido. Urban Studies, v. 50, n. 1, p. 148168, 2013. Disponível em: https://doi.org/10.1177/0042098012452329. Acesso em: 16 ago. 2020.

FRANGELLA, S. M. Corpos urbanos errantes: uma etnografia da corporalidade de moradores de rua em São Paulo. 2004.361 f. Tese (Doutorado em Antropologia) Universidade Estadual de Campinas. Instituto de Filosofia e Ciências Humanas.

Campinas, SP: 2004. Disponível em: 
file:///C:/Users/gilsons/Downloads/Frangella_SimoneMiziara_D.pdf. Acesso em: 13 set. 2020.

IBGE. Estimativa populacional. 2020. Disponível em: https://www.ibge.gov.br/cidadese-estados/pr/cascavel.html. Acesso em: 10 ago. 2020.

IPEA - INSTITUTO DE PESQUISA ECONÔMICA APLICADA. 2015. Disponível em:

https://www.ipea.gov.br/portal/index.php?option=com_content\&view=article\&id=2930 3.Acesso em: 11 de set. 2020.

MAFFESOLI, M. O tempo das tribos: o declínio do individualismo nas sociedades de massa. Rio de Janeiro: Forence, 1998.

MAFFESOLI, M. sobre o Nomadismo: vagabundagens pós-modernas. Rio de Janeiro. Record, 2001.

MAGNI, C. T. Povo da rua: um estudo sobre o nomadismo urbano. São Paulo: Coleção Cadernos da Cidade, 1995.

MATTIELO, F., RAMOS, W. M. Estudos em psicologia e áreas interdisciplinares sobre a população em situação de rua. Estudos de Psicologia, v.23 n.1, p.67-77, 2018.

Disponível em: http://pepsic.bvsalud.org/scielo.php?script=sci_arttext\&pid=S1413294X2018000100008. Acesso em: 14 set. 2020.

MENDES, K. T.; RONZANI, T. M.; PAIVA, F. S. População em situação de rua, vulnerabilidades e drogas: uma revisão sistemática. Psicol. Soc., Belo Horizonte, v. 31, 2019. Disponível em: https://www.scielo.br/scielo.php?pid=S0102-

$71822019000100239 \&$ script=sci_abstract\&tlng=es. Acesso em: 10 de set. 2020.

MELITO, L. População de rua deve ficar fora do Censo 2020. Agência Brasil. Brasília: 2018. Disponível em: https://agenciabrasil.ebc.com.br/direitoshumanos/noticia/2018-09/populacao-de-rua-deve-ficar-fora-do-censo-2020. Acesso em: 15 set. 2020 .

MONTIEL, J. M., et al. Avaliação de Transtornos da Personalidade em Moradores de Rua. Centro Universitário Fundação Instituto de Ensino para Osasco. Universidade São Francisco. Psicologia: ciência e profissão, 2015, v.35 n,2, p.488-502. Disponível em: https://www.scielo.br/scielo.php?pid=S1414-

98932015000200488\&script=sci_arttext\&tlng=pt. Acesso em: 11 set. 2020.

ROCHA, A. L. C.; ECKERT, C. Etnografia de rua: estudo de antropologia urbana. Revista do Núcleo de Desenvolvimento da Criatividade da UNICAMP. Campinas. $n$. 9, p. 101-127, 2003. Disponível em:

https://portalseer.ufba.br/index.php/rigs/article/view/12527. Acesso em: 10 set. 2020.

RUI, T. C. Corpos abjetos: etnografia em cenários de uso e comércio de crack.

Tese de doutorado. Campinas, SP, 2012. Disponível em:

http://repositorio.unicamp.br/handle/REPOSIP/280382. Acesso em: 14 set. 2020. 
SANCHEZ, A. I. M.; BERTOLOZZI, M. R. Pode o conceito de vulnerabilidade apoiar a construção do conhecimento em Saúde Coletiva? Ciência Saúde Coletiva. v. 12, n.2. p. 319-324. 2007. Disponível em: https://www.scielo.br/pdf/csc/v12n2/a07v12n2.pdf. Acesso em: 13 set. 2020.

SILVA, I. C. N., et al. Social representations of health care by homeless people. Rev. Esc. Enferm. da USP. São Paulo: 2018. Disponível em:

https://www.scielo.br/scielo.php?pid=S0080-

62342018000100409\&script=sci_arttext\&tlng=pt. Acesso em: 16 ago. 2020.

Recebido em: 15/09/2021

Aprovado em: 05/10/2021

Publicado em: 10/10/2021 